\title{
Medievalista
}

\section{Os cavaleiros do Graal e o anti-heroísmo hagiográfico}

\section{Ana Margarida Chora}

\section{OpenEdition}

\section{Journals}

\section{Edição electrónica}

URL: http://journals.openedition.org/medievalista/698

DOI: $10.4000 /$ medievalista.698

ISSN: 1646-740X

\section{Editora}

Instituto de Estudos Medievais - FCSH-UNL

Edição impressa

Data de publição: 1 Junho 2012

\section{Refêrencia eletrónica}

Ana Margarida Chora, « Os cavaleiros do Graal e o anti-heroísmo hagiográfico », Medievalista [Online] 12 | 2012, posto online no dia 19 fevereiro 2014, consultado no dia 20 abril 2019. URL : http:// journals.openedition.org/medievalista/698 ; DOI : 10.4000/medievalista.698

(C) IEM 
Título: Os cavaleiros do Graal e o anti-heroísmo hagiográfico

Autor(es): Ana Margarida Chora

Enquadramento Institucional: Centro de Estudos sobre o Imaginário Literário FCSH UNL

Contacto: ana.chora@ vizzavi.pt

Fonte: Medievalista [Em linha]. №12, (Julho - Dezembro 2012). Dir. José Mattoso.

Lisboa: IEM.

Disponível em: http://www2.fcsh.unl.pt/iem/medievalista/

ISSN: $1646-740 \mathrm{X}$

Data do artigo: Abril, 2011

\section{Resumo}

Os heróis medievais arturianos que, nos textos da Vulgata e Post-Vulgata, estão destinados à aventura do Graal (Lancelot, Boorz, Persival e Galaaz) seguem um percurso que em muito se assemelha aos dos santos das narrativas da mesma época, passando pela predestinação e mudança de conduta, a partir de um determinado momento, o que os conduz à vida espiritual. Mas se, por um lado, as suas características heróicas determinam a especificidade da sua evolução ascética, por outro lado os percursos hagiográficos das narrativas medievais assumem contornos que tocam o anti-heroísmo.

Palavras-chave: herói, santo, hagiografia, Matéria da Bretanha, esquema heróico

\section{Abstract}

Medieval Arthurian heroes who, in the Vulgate and Post-Vulgate texts, are destined to the Grail adventure (Lancelot, Boorz, Perceval and Galaad) follow a very similar pathway to those of saints narratives of the same period, which goes through 
predestination and change of behaviour, from a certain moment, taking them to spiritual life. But if, on the one hand, their heroic characteristics determine the specificity of their ascetic evolution; on the other, hagiographic pathways in medieval narratives have forms that touch anti-heroism.

Keywords: hero, saint, hagiography, Matter of Britain, heroic scheme

\title{
Os cavaleiros do Graal e o anti-heroísmo hagiográfico
}

\author{
Ana Margarida Chora
}

\section{Cavalaria e edificação espiritual}

Os textos literários medievais estão povoados de personagens que, como modelos de conduta, parecem ultrapassar em larga medida os limites da condição humana, quer em percurso, quer em força tanto exterior como interior. Em dois pólos opostos, ainda que complementares, situam-se os heróis e os santos, como pretendemos demonstrar neste estudo comparativo, cuja principal motivação é centrada na questão da excepcionalidade, que assume contornos distintos quando se trata de santos e heróis que, enveredando por caminhos de singular condição, se distinguem tanto em função das suas escolhas, como em função daquilo a que estão predestinados.

No ciclo literário arturiano da Vulgata e Post-Vulgata (século XIII), encontramos heróis que desafiam as fronteiras intocáveis dos percursos hagiográficos, colocando-se em planos paralelos aos santos em termos do seu processo evolutivo. Referimo-nos 
concretamente aos cavaleiros do Graal: Lancelot ${ }^{1}$, Boorz, Persival e Galaaz ${ }^{2}$. O primeiro por estar inicialmente destinado à santa missão e ter sido afastado devido ao pecado. Os restantes por terem chegado, efectivamente, à suprema aventura do cálice sagrado. Em qualquer dos casos, os cavaleiros parecem desenhar um percurso edificante, que culminará na ascese e santificação.

Iremos comparar os percursos heróicos dos cavaleiros do Graal, presentes nos textos arturianos, com os percursos de santidade, partindo dos marcos que estabelecem a diferenciação em relação ao mundo que constam de alguns exemplos de narrativas hagiográficas medievais, tomando como base um corpus textual relativo às aventuras do Graal, que compreende os feitos heróicos destas personagens, sendo que numa instância comparativa tomaremos como exemplo algumas características do percurso dos santos contidos designadamente no Flos Sanctorum, em virtude de se tratar de narrativas que encerram os pontos cruciais da maturação, a par das ficções heróicas dos cavaleiros de que nos ocupamos: a predestinação, as escolhas que determinam a evolução, culminando na incorporação ou separação dos mundos em que vivem respectivamente os heróis e os santos. Assim, apesar de heróis e santos serem personagens com características distintas e oriundas de textos muito diversos, a sua colocação em paralelo surge da necessidade do confronto estrutural, ao nível dos esquemas que sustentam o imaginário medieval, entre os conceitos de santidade e heroísmo, tendo em conta o que os distingue e o que os aproxima, com o intuito de verificar nos cavaleiros do Graal a existência de um percurso de maturação que evolui para a santidade. Como tal, esta reflexão comparativa não incide tanto no confronto de textos, mas antes na análise do trajecto heróico à luz do destino ascético.

\footnotetext{
1 Apesar de o nome aparecer também sob as formas "Lançarot" e "Lançalot" na Demanda do Santo Graal, mantemos aqui a versão pela qual é mais conhecido enquanto figura central do Lancelot-Graal.

${ }^{2}$ Conhecidos pelas variantes Boors, Perceval e Galaad nos textos da Vulgata.
} 


\section{Heroísmo e santidade}

O herói arturiano caracteriza-se por descrever um percurso identitário singular, condicionado pelo seu nascimento e modificado ao longo do seu processo de maturação, de acordo com as suas acções e as de outras personagens. O nascimento geralmente ocorre em situações especiais, entre as quais se contam as manipulações mágicas e o secretismo que envolve a sua concepção, o que determina a predestinação. Curiosamente, o herói com uma infância feérica mais marcante, Lancelot, é aquele que acaba por revelar uma postura mais edificante, equiparada aos esquemas das vidas de santos. Lancelot é aquele que, para além de personagem central do ciclo arturiano, mais mutações sofre, não só ao longo do seu percurso heróico como ao longo da tradição textual que recria o mito.

Segundo John Lash, a condição heróica pressupõe uma capacidade superior de força física e moral que ultrapassa os demais. Lash propõe três variantes do herói: o guerreiro, o santo (ou sábio), e o salvador, sendo que os dois últimos são, na verdade, desvios relativamente à sua expressão primária (a do guerreiro), pois enquanto o último incorpora o desafio a forças que excedem os limites, os primeiros personificam o equilíbrio alcançado pelo aperfeiçoamento dos poderes da mente e do espírito. Relativamente ao santo, "he is the idealization of the human norm, while the hero is supranormal" "3. Por seu turno, o salvador é aquele que provoca a compensação, de forma a repor a lei cósmica, que é diferente da actuação do herói, na medida em que este se limita a proteger e a salvar, e não a redimir e a recuperar. A acção do santo, por sua vez, confina-se a repelir manifestações exteriores de força, de forma a conservar a sua tranquilidade interior, ao contrário do herói, que absorve essas manifestações violentamente. Notemos que, no caso dos cavaleiros arturianos do Graal, essas manifestações são integradas na composição heróica das personagens. Lash faz notar que são poucos os heróis-santos simultaneamente veementes e pacíficos. Em

\footnotetext{
${ }^{3}$ LASH, John - The Hero. London: Thames and Hudson, 1995, p. 6.
} 
contrapartida, Joseph Campbell caracteriza o santo como "the word-renouncer", que parte para o isolamento, "that from which there is no return".

Os cavaleiros arturianos manifestam heroísmo não só nas suas acções como no esquema evolutivo que descrevem. São sujeitos a uma existência excepcional, condicionada desde o nascimento à morte. $\mathrm{E}$ as aventuras por que passam determinam tanto a sua maturação como a situação que se vive no reino de Logres, onde reina Artur, sujeito ao destino que lhe vão proporcionar os seus cavaleiros, que podem ou não favorecê-lo com a sua actuação.

A demanda do Graal implica um caminho de iniciação individual, que se funda na pureza e na renúncia, culminando na visão do Graal, prova máxima do merecimento, equiparada à santificação. Essa visão coincide com a salvação do rei Pescador, cujo reino permanece devastado enquanto o de Artur floresce. Mas, ao mesmo tempo, a realização da proeza está sujeita à eleição de um cavaleiro predestinado, pelo que entrar na demanda do Graal é, à partida, mais uma opção de renúncia, com vista a atingir a santidade, do que a busca do Graal em si mesmo. E o apogeu do reino de Artur só subsiste enquanto não cair em decadência com a ascensão do reino do Graal, pelo que não se justifica o regresso à vida cavaleiresca depois de se ter entrado na mais alta aventura, a do Graal.

No entanto, o reino do Graal não é o único com o qual o de Logres disputa a hegemonia. Antes disso, já Lancelot, herói ligado ao mundo feérico, salvara o reino de Artur vencendo Méléagant, do reino de Gorre, que havia raptado a rainha Guenièvre, levando consigo o elemento feminino, símbolo da supremacia e fertilidade, que passa, por alternância, de um reino para outro ${ }^{5}$, sendo a história narrada em Le Chevalier de la Charrete de Chrétien de Troyes, do final do século XII.

Lancelot desenvolve, a partir daí, um percurso heróico, do qual se compõe. Vai ao Outro Mundo, para fazer girar o tempo e para permitir a alternância. Mais tarde, vai ao

\footnotetext{
${ }^{4}$ CAMPBELL, Joseph - The Hero with a Thousand Faces. New York: Princeton University Press, 1973, p. 354.

5 cf. GODINHO, Helder - "A Poesia, o Amor e a concepção do Mundo". In GODINHO, Helder (org.) - A Imagem do Mundo na Idade Média: actas do colóquio internacional. Lisboa: ICALP, 1992. pp. 35-39.
} 
reino feérico de Morgain, no Lancelot en prose, texto do século XIII, mas fica preso no tempo feminino, imóvel e irresistivelmente perigoso. Passa por castelos encantados, fica com Galehot em Sorelois, um reino encantado, e é disputado entre os dois mundos, porque ele é um herói com uma dupla natureza, cavaleiresca e feérica, devido à sua origem real e à sua criação por uma fada. Por culpa do seu envolvimento pecaminoso com a rainha Guenièvre (ou Genevra, na Demanda do Santo Graal), não foi iluminado com a visão do Graal, mas teve as visões dos sonhos que o levam ao arrependimento e à entrada voluntária no serviço religioso. E só desse mundo divino é que não regressa. Mas há que sublinhar que a atitude de Lancelot foi voluntária. Tinha sido ele o eleito para a visão do Graal, mas fez as suas escolhas, agindo sempre de acordo com a sua consciência, e a sua maturação assumiu contornos diferentes dos inicialmente previstos $^{6}$. Na Demanda do Santo Graal, Lancelot sabe que será ultrapassado pelo seu filho Galaaz, pois o seu destino ficara comprometido com o pecado. Lancelot sabe que não é mais o escolhido quando recusa retirar a espada do padrão que fora parar à ribeira junto ao paço de Artur ("nom valho eu tanto que deva meter mão em arma de tal homem com aquele será que esta espada há-de trazer"7), aventura incipiente da busca do Graal.

A par de Lancelot, Boorz surge ligado à mesma origem feérica, mas o seu percurso está condicionado a Galaaz, funcionando como um duplo deste na demanda do Graal. Boorz desenvolve uma acção fundada na força heróica, lutando como campeão de damas e donzelas (especialmente deserdadas e desonradas ${ }^{8}$ ), transmitindo a imagem do bom espírito cavaleiresco.

E Persival, cujo caminho em direcção ao Graal remonta a Li Contes del Graal de Chrétien de Troyes (onde surge como Perceval li Gallois), também envereda por um percurso heróico à semelhança dos demais, ajudando donzelas e passando por provas

\footnotetext{
${ }^{6}$ cf. CHORA, Ana Margarida - Lancelot - do mito feérico ao herói redentor. Lisboa: Colibri, 2004.

${ }^{7}$ A Demanda do Santo Graal. Ed. Irene Freire Nunes. Lisboa: I.N.C.M., 1995, 11, p. 26.

${ }^{8}$ La Queste del Saint Graal: roman du XIIIe siècle (atr. a Gautier Map). Ed. Albert Pauphilet. Paris: Honoré Champion, 1980.
} 
cavaleirescas para poder sentar-se no lugar da Távola Redonda ${ }^{9}$ reservado a um cavaleiro predestinado.

\section{Predestinação e escolha}

A origem do destino heróico situa-se claramente na infância. Lancelot fora criado por uma fada, a Dama do Lago, passando os seus primeiros anos num ambiente mágico ${ }^{10}$. A sua divisão enquanto personagem reside no facto de pertencer simultaneamente ao mundo real e ao mundo feérico, factor que lhe irá permitir transitar entre eles. Boorz, seu primo, também havia sido criado pela fada do lago, tendo passado a infância nas mesmas condições. Assim sendo, estes heróis estão nitidamente orientados para o futuro cavaleiresco.

Quanto a Persival, a sua infância é caracterizada por um afastamento em relação ao mundo, já que a mãe o cria sozinha na floresta (episódio relatado no Li Contes del Graal de Chrétien de Troyes), longe do conhecimento que gera a cisão necessária à formação do herói. Persival vai separar-se desse mundo inicial de perfeição quando entra na cavalaria arturiana. Apesar de ligar-se à cavalaria, o seu destino já estava marcado para a santa aventura do Graal, como veremos adiante.

Galaaz, por sua vez, é concebido por manipulação (com a ajuda de Brisane, que ilude Lancelot com o semblante de Elaine, filha do rei do Graal, fazendo-o crer que se trata da rainha Guenièvre ${ }^{11}$ ), pelo que a sua concepção tem o propósito da missão que veio a levar a cabo, desenvolvendo o herói todo um caminho destinado à santidade.

A entrada na aventura do Graal e, consequentemente, na vida espiritual, dá-se por razões diferentes: Lancelot teria sido o cavaleiro perfeito para a aventura, mas foi afastado pelo pecado, redimindo-se com o arrependimento. Boorz foi companheiro de

\footnotetext{
${ }^{9}$ Le Didot-Perceval, according to the manuscripts of Modena and Paris. Ed. William Roach. Genève: Slatkine, 1977, E, pp. 149-165.

${ }^{10}$ Lancelot: roman en prose du XIIIe siècle. Ed. Alexandre Micha. 9 vols. Genève: Droz, 1978-1983, IIIa, 8-9, vol. VII, p. 28.

${ }^{11}$ Lancelot, CV, 34, vol. VI, p. 174.
} 
Galaaz, mas a suprema aventura não lhe foi reservada por ter cometido pecado carnal, rompendo o pacto com Deus, que pressupunha a manutenção da virgindade, tendo concebido Alaim o Branco ("Alaim o Branco foi filho de Boorz de Gaunes e feze-o em ũa filha del-rei de Gram Bregonha" ${ }^{\prime 2}$ ). Boorz emendou-se, passando a viver sob um regime de castidade. Porém, só Galaaz fora o eleito.

Para Lancelot e Boorz, a vida ascética pode ter sido a consequência de uma aventura falhada. E a santidade indissociável da escolha própria. Todavia, o comprometimento de Persival com o divino surge em tenra idade (aspecto que apenas aparece no DidotPerceval ${ }^{13}$ ), estando a sua investidura ligada à visão do Espírito Santo que o seu pai, Alain le Gros, tem antes de morrer, e que revela a missão do seu filho (Perceval) na salvação do rei Pescador, seu antepassado (“Et je coment a ton fiz qu'i[1] s'en voit a la cort a celui roi que l'en apele rois Artus, et la aprandra teles novelles par quoi il vandra a la maison son aiol le riches Rois Picheors" ${ }^{\text {14 }}$ ). O destino de Persival assume, pois, um compromisso que é alheio à sua vontade, mas que é uma marca da sua predestinação, orientada para um fim específico.

A santidade corresponde a uma divisão dos mundos, a qual pode ser causada por várias situações: numa, o santo é escolhido, quer pelo desdobramento da paternidade (dividida entre os pais e Deus), quer pelas visões que experiencia; noutra, é o santo que procede à decisão, através do arrependimento. Muitos santos devem a sua santidade não à iniciativa própria, mas à vontade alheia ou, melhor dizendo, à "vontade paterna", seja ela humana ou divina. A santidade, ou o caminho para ela, caracteriza-se por uma passagem para um "outro mundo", divino, que se opõe ao nosso mundo (neste caso, o mundo secular), passagem a partir da qual o santo já não regressa.

A condição para a santidade está, à partida, predestinada, uma vez que o santo é escolhido pelos pais ou por Deus. Porém, qualquer uma das formas de passagem para o Outro Mundo espiritual constitui um momento de separação, de cisão dos mundos.

\footnotetext{
${ }^{12}$ Demanda, 14, p. 28.

13 Trilogia do século XIII (composta por Joseph, Merlin, Perceval), baseada nos textos de Robert Boron, também conhecida como Perceval en prose ou Perceval de Modène.

${ }^{14}$ Didot-Perceval, D, p. 139.
} 
No primeiro caso, a promessa dos pais compromete o futuro santo com um mundo do qual já não pode regressar, uma vez que o pai celeste vem reclamar simbolicamente o filho que trouxe ao mundo sob alguma condição. Trata-se do paradigma do filho longamente desejado, segundo o qual os pais, geralmente inférteis ou muito crentes, prometem a Deus o filho que possam vir a gerar. Muitas são as vidas dos santos que começam neste momento temporal. Algumas narrativas hagiográficas demonstram esta questão. No Flos Sanctorum ${ }^{15}$, alguns santos são condicionados à nascença por esta divisão simbólica. É o que acontece com São Giraldo (“seus parentes eram de grande maneira pessoas tementes a Deos, e antes que casassem, feze//rom voto ao senhor Deos que o primeiro fruito de seu matrimonio offerecessem a Deos para sempre. (...) $\mathrm{O}$ Senhor, veendo o seu mui desejo, lhes deu fruito de bençom e nascendo o moço foi dado a criar como lhe pertencia"16), Santo Atillano ("como seu padre por longo tempo muito desejasse geeraçom (...) o prometeo e o offereceo ao templo de sam Bernardo" ${ }^{17}$ ), e São Bernardinho ("forom compridos seus sanctos desejos e houverom huũ filho, o qual nasceo no oitavo dia de Setembro que é dia da nascença de Nossa Senhora, a Virgem Gloriosa" ${ }^{\text {"18 }}$ ). O mesmo se passa com a Virgem Maria, cujos pais, Santa Ana e São Joaquim, a comprometem com o divino ("sempre forom maninhos e nom quis Deos dar lhes fruito de bençom, (...) fezerom voto e prometimento a Deos que se lhes desse alguũ de geraçom que lho offrecerom"19).

O destino de Persival não é regido pela infertilidade dos pais. Mas a sua predestinação é marcada na infância, correspondendo à segunda situação, em que o santo sofre um chamamento divino através de uma visão, a qual constitui não só sinónimo de eleição, como indício de uma excepcionalidade que o coloca num lugar à parte, apesar de não ser o próprio Persival a ter a visão, mas sim o pai.

Galaaz é o escolhido na Demanda do Santo Graal. É o cavaleiro predestinado a vislumbrar o Graal. Já era facto conhecido e esperado por todos que era ele que havia de

15 Ho Flos Sanctorum em Lingoagẽ: os Santos Extravagantes. Ed. Maria Clara de Almeida Lucas. Lisboa: INIC, 1988.

${ }^{16}$ Flos Sanctorum, p. 169.

${ }^{17}$ Flos Sanctorum, pp. 25-26.

${ }^{18}$ Flos Sanctorum, p. 113.

${ }^{19}$ Flos Sanctorum, p. 260. 
"dar cima aas aventuras do Santo Graal"20. Logo no início da Demanda, o eremita da igreja onde o jovem herói é armado cavaleiro manifesta o seu júbilo por ter consigo o herói predestinado:

"Ca Deus (...) te dará poder e força e bondade de armas e de ardimento sobre todolos cavaleiros que nunca trouxerom armas no regno de Logres, assi que tu darás cima a todalas outras maravilhas e aventuras u todolos outros falecerom e falecerám." ${ }^{21}$

Ao sentar-se na sédia perigosa, de acordo com o que já era sabido, Galaaz é visto como "o cavaleiro per que seriam acabadas as aventuras do Regno de Logres" Galaaz é o que está escrito no lugar só a ele reservado ("E el-rei se ergueu da mesa e foi aa mesa u siia Galaaz, e viu i seu nome escrito",23).

Aliás, as suas acções estão submetidas à predestinação, nomeadamente quando consegue retirar a espada do padrão que se encontrava na ribeira de Camalot ("Entam filhou Galaaz a espada polo mogoram e tirou-a tam ligeiramente como se nam tevesse em rem"24), quando lê as letras da nave que conduz o trio do Graal à aventura de Caifáz ("E sabede que nom soube Galaaz leer as leteras mas aquele Senhor que muito fremoso milagre e muitas fremosas virtudes havia feitas por ele mostrou-lhe entom tam grande sinal de amor que lhe fez logo saber caldeu" ${ }^{, 25}$ ), ou quando consegue retirar a espada da bainha das "estranhas correas",26 a ele destinada ("Entom se sinou e sacou a espada tam ligeiramente da bainha como quis" ${ }^{27}$ ).

\footnotetext{
${ }^{20}$ Demanda, 16, p. 30.

${ }^{21}$ Demanda, 5, p. 22.

${ }^{22}$ Demanda, 17, p. 30.

${ }^{23}$ Demanda, 19, p. 31.

${ }^{24}$ Demanda, 19, p. 32.

${ }^{25}$ Demanda, 416, pp. 312-313.

${ }^{26}$ Demanda, 420, p. 315.

${ }^{27}$ Demanda, 416, p. 312.
} 
Apesar de manifestar marcas da sua predestinação, Galaaz não tem nenhuma visão a partir da qual mude de conduta ou tome conhecimento da sua missão, tipicamente presente naquilo que caracteriza a mudança de vida dos santos. Antes pelo contrário, os seus actos já estão sujeitos a essa eleição. No dizer de Peter Brown, "les grands hommes du III ${ }^{\mathrm{e}}$ siècle avaient été ceux dont les visions manifestaient qu'ils jouissaient d'un degré exceptionnel de proximité avec leurs invisibles gardiens" 28 . Não existe uma visão divisória do percurso de Galaaz. No entanto, ele toma contacto com o seu destino através, essencialmente, de vozes. Ele ouve uma voz que lhe revela que o rei Peleam será curado com a sua vinda ("- Galaaz, leva suso e filha aquel bacio de sô aquela lança e vai-te a rei Peleam e entorna-lho sobolas chagas ca assi há-de guarecer per ta vĩinda” ${ }^{, 29}$ ), ouve uma voz que o conduz à barca dos cavaleiros do Graal $^{30}$, ouve outra voz que lhe anuncia que Deus fará a vontade da sua morte quando esta for pedida (“Galaaz, Nosso Senhor fará ta vontade desto que lhi pedes ca aquela hora que tu pidires ta morte havê-la-ás e acharás vida de alma e ledice perdurável”31). Aliás, Galaaz é o único a receber avisos que sabe interpretar. As visões de outros heróis, através de sonhos, são explicativas do seu pecado, e eles não as sabem interpretar a não ser com a ajuda de mediadores.

A luz está reservada a Galaaz na contemplação do Graal. Mas essa luz não marca uma mudança de condição, pois a sua condição já era, à partida, diferente da dos demais. Galaaz já estava orientado para a santidade, contrariamente aos esquemas hagiográficos, os quais prevêem um momento de divisão do tempo. O santo, se não estiver comprometido à nascença com o seu destino, há-de passar pela experiência da luz que faz o corte com o passado. Isso acontece com santos como São Victores ("e assi logo enviou um anjo do ceeo ao glorioso martire sam Victores”32), São Marçal ("Em aquelle tempo lhe apareceo esse mestre Jhesu Christo (...). Apareceo lhe pois com grande claridade e resprandor" ${ }^{\text {33 }}$ ), São Gonçalo de Amarante, a quem a Virgem mandou entrar na ordem dos frades marianos pregadores ("apareceo lhe lume de gloria alumiante toda

\footnotetext{
${ }^{28}$ BROWN, Peter - Le Culte des Saints. Paris: Cerf, 1996, p. 73.

${ }^{29}$ Demanda, 594, p. 434.

${ }^{30}$ Demanda, 521, p. 382.

${ }^{31}$ Demanda, 620, p. 452.

${ }^{32}$ Flos Sanctorum, p. 70.

${ }^{33}$ Flos Sanctorum, p. 194.
} 
a cella e a Virgem gloriosa"34), São Heleno ("foi se ao deserto e i por refrear a carne começou de jejũar (...) dormio huũ pouco e apareceu lhe o anjo em visom" ${ }^{\text {"35 }}$ ), e São Giraldo ("Já a graça devinal reluzia em o seu servo, assi que todos the haviam hũa sancta enveja (...) conhecendo o lume de Deos resplandecer em elle"36). O santo assiste, pois, a uma visão que modifica o seu percurso, alterando a sua conduta.

\section{Mudança de condição}

O caminho para a santidade pode ser desenhado a partir do chamamento divino, situação que condiciona igualmente a santidade, tal como aconteceu na eleição divina de Persival, aquando da visão do seu pai, como vimos. O aparecimento de uma luz é o momento de cisão, correspondente a um apelo exterior. A "luz" que aparece ao santo é simbolicamente vertical e, tal como a luz do meio-dia, não deixa lugar para a sombra. Logo, a sombra, ou duplo do santo, é deixada no mundo exterior. O santo só encontra a sua imagem reflectida na divindade, entidade do Outro Mundo que o absorve e não permite sair dele. É a consequência da mudança de condição prevista no percurso hagiográfico. De acordo com Mircea Eliade, “por vezes, a alteração de regime sensorial provocada pela «eleição» sobrenatural é facilmente compreensível. O homem tocado impunemente pelo raio adquire uma «sensibilidade» inacessível ao nível da experiência profana; a revelação da «escolha» divina manifesta-se pela destruição de todas as estruturas anteriores: o «eleito» torna-se um «outro» - sente-se não só «morto e ressuscitado», mas também nascido noutra existência que, parecendo seguir-se neste mesmo mundo, baseia-se em outras dimensões existenciais" ${ } 37$.

A luz é também aquilo que se opõe às trevas, correspondendo respectivamente à Ordem e ao Caos. Deus pôs Ordem sobre o Caos ao criar o Cosmos. E o santo comunga dessa luz. Por outro lado, segundo Mircea Eliade, a presença da luz é sintomática de uma iniciação. No caso dos santos, a iniciação implica uma mudança de condição: "Le Saint-

\footnotetext{
${ }^{34}$ Flos Sanctorum, p. 163.

${ }^{35}$ Flos Sanctorum, p. 135.

${ }^{36}$ Flos Sanctorum, p. 169.

${ }^{37}$ ELIADE, Mircea - Mitos, Sonhos e Mistérios. Lisboa: Ed. 70, s.d., p. 90.
} 
Esprit est représenté comme une flamme; la sanctification est exprimée par des images de feu ou de flamboiement. On a là une des sources doctrinales de la croyance que la perfection spirituelle - c'est-à-dire la sainteté - non seulement rend l'âme capable de voir le corps de lumière du Christ, mais qu'elle s'accompagne également de phénomènes extérieurs: le corps du saint irradie la lumière ou brille comme un feu brûlant" ${ }^{38}$. Há, pois, uma alteração no santo, cuja vida se divide a partir da visão divina.

A luz, que pode ser interior ou exterior, pode aparecer, nas narrativas hagiográficas, acompanhada de elementos decorativos (nomeadamente pedras preciosas), brilho, cores e aspectos afins. Surgem alguns santos com estas particularidades, como Santo Atillano, no seu milagre ("Deos que tem o ceptro e poderio de todas as cousas humanas e divinas, vestio diante todo o povoo a sam Atillano de hũa vestidura mui clara"39). Esta imagem assemelha-se à visão do Graal, cuja luz indicia o culminar da iniciação à santa aventura.

O aparecimento da luz é sinónimo de tudo o que está ligado à predestinação divina: eleição, de conhecimento divino vedado aos comuns, união com o sagrado, perfeição, pureza, condição superior e santidade. O branco da luz está, por sua vez, associado ao elemento do Outro Mundo. Galaaz também tem visões em que contempla a claridade divina. Contudo, estas não se revestem de um carácter iniciático, mas sim de confirmação do seu percurso. Galaaz tem uma visão, em sonhos, que o avisa da sua morte e outra que lhe indica o seu destino de não regressar ao reino de Logres, sendo que o único que havia de voltar seria Boorz:

"Aquela noite aveo que jazia dormindo Galaaz e veo a ele ũũ homem mui fremoso vestido de ũus panos brancos, e disse-lhi (...):

\footnotetext{
${ }^{38}$ IDEM - Méphistophélès et l'Androgine. Paris: Gallimard, 1995, p. 81.

${ }^{39}$ Flos Sanctorum, p. 28.
} 
- Tu pensas se tornarás ainda ao reino de Logres ou se o Santo Vaso i tornará. E te digo que tu ja mais nom tornarás ao reino de Logres, nem Persival, mas Boorz i tornará." 40

\section{Arrependimento e santificação}

A terceira situação de evolução para a santidade relaciona-se com o arrependimento. As narrativas hagiográficas, designadamente as da obra de Jacobus de Voragine (Jacques de Voragine), Legenda Aurea (La Légende Dorée), do século XIII, referem essencialmente as vidas dos santos mártires, eremitas e membros eclesiásticos, reservando os relatos de arrependimentos para as mulheres (como Maria Egipcíaca, Santa Pelágia, Maria Madalena e Thaís), exceptuando-se alguns casos, como o de São Julião, cuja vida surge no Flos Sanctorum de 1513, que se arrependeu e obteve o perdão de Deus ${ }^{41}$, e São Nicolau (mencionado na narrativa de São Patrício ${ }^{42}$ ).

Mas os cavaleiros do Graal, no seu caminho de santificação, deparam com um processo que se desenrola em duas vertentes: a tentação e a consciencialização do pecado. Boorz sofre a tentação do demónio. Persival, na Queste (surgindo como Perceval), parte intermédia da Vulgata que sucede o Lancelot en prose e precede a Mort Artu, sofre tentações de demónios disfarçados de belas donzelas ("Se tu vouloies, fet ele, creanter que tu feroies ma volenté quant je t'en semondroie, jel te donroie orendroit bon et bel, qui te porteroit la ou tu voldroies"43). Lancelot sofre a tentação de voltar a cair em pecado com a rainha.

Consequentemente, os heróis do Graal, à excepção de Galaaz, sofrem a reprovação, quer através de outras personagens, quer de vozes que ouvem e que os confrontam com pecados cometidos. As vozes que estes heróis ouvem são anunciadoras ou reprovadoras,

\footnotetext{
${ }^{40}$ Demanda, 622, p. 453.

${ }^{41}$ LUCAS, Maria Clara de Almeida - Hagiografia Medieval Portuguesa. Lisboa: ICALP, 1984, pp. 107108.

${ }^{42}$ IDEM - A Literatura Visionária na Idade Média Portuguesa. Lisboa: ICALP, 1986, pp. 137-139.

${ }^{43}$ Queste, p. 91
} 
chamando-os à consciência. E as visões são veiculadas em sonhos passíveis de serem interpretados.

Boorz (Boors na Queste) tem uma visão, interpretada como simbolizando o seu pecado carnal $^{44}$. Persival sofre reprovação por várias damas e donzelas ${ }^{45}$, por não ter feito as perguntas sobre o Graal aquando da visita ao castelo. Mas o herói que mais se arrepende e maior transformação sofre é Lancelot.

$\mathrm{Na}$ Queste, Lancelot ouve uma voz numa ermida que reprova a sua conduta pecaminosa, fazendo-o lamentar-se do seu pecado de luxúria com a rainha Guenièvre. $\mathrm{O}$ caminho do arrependimento dá-se através da confissão, exteriorizando discursivamente o pecado ("car des lors que je fui primes chevaliers ne fu il hore que je ne fusse coverz de teniebres de pechié mortel, car tout adés ai habité en luxure et en la vilté de cest monde plus que nus autres"46). É aqui que o herói começa a consciencializar o pecado. E, ao chegar à câmara do Graal, no castelo do rei Pescador, Lancelot é afastado por uma voz $^{47}$. Aproxima-se da câmara do Graal, no castelo de Corbéric, mas uma voz impede-o de se aproximar do Santo Vaso:

"Entom catou de todas partes e poderia veer alguém que o destorvasse de entrar alá, ca ele queria ir até a santa mesa e descobrir o Santo Vasco (sic) por veer que i havia.

Entom ouiu ũa voz que lhi disse:

- Lançalot, nom entres dentro ca ti nom é outorgado."

\footnotetext{
${ }^{44}$ Queste, p. 179.

${ }^{45}$ Didot-Perceval, E, pp. 210-211 e p. 220.

${ }^{46}$ Queste, pp. 61-62.

${ }^{47}$ Queste, p. 255.

${ }^{48}$ Demanda, 547, p. 401.
} 
Lancelot tem visões, sob a forma de sonhos, que denunciam simbolicamente o pecado. E é a partir delas que muda de conduta, renunciando à vida mundana:

"Aquela visam que a Lamçarot aveo entam foi tal:

Semelhava-lhe que chegava a ũũ rio, o mais feo e o mais espantoso que nunca vira, e que nom poderia homem entrar em el que nom fosse morto.

E ele catava o rio e nom ousava i entrar, ca o via cheo de coobras e de vermẽes (...)."

As visões acabam por ser separadoras ao nível do caminho a seguir, apesar de não se manifestarem em estado luminoso. É assim que Lancelot verbaliza a promessa de não voltar a pecar, vestindo uma estamenha como acto de contrição:

“- Muito me pesa de já aqui vĩir e acho-me atam mal que mais quiria nunca vencer armas ca me veerem, que já pormiti ante o Senhor nunca tornar e prometo-o outra vez. (...). E ũũ dos irmitães filhou logo ũa estamenha e muito áspera e deu-a a Lançarot. E disse-lhe:

- Eu quero que vestades esta vistidura a caram da carne em nome de pendença entramente andardes na demanda do Santo Graal.

E ele a filhou e vestiu-a e foi-se assi que nunca despois a despiu atá que tornou a casa del-rei Artur que tornou a cometer e fazer o pecado dante como o fazia." 50

O processo de arrependimento marca outro tipo de momento divisório na vida dos heróis. Os que haviam realizado proezas guerreiras e mundanas passam para outra dimensão, espiritual, apartada dos prazeres materiais. Lancelot começa a renunciar à

${ }^{49}$ Demanda, 201, p. 158.

${ }^{50}$ Demanda, 218, pp. 174-175. 
carne suportando a dor física, envergando a estamenha, como forma de separação em relação ao mundo.

Uma característica fundamental da passagem para o Outro Mundo espiritual é suportar as dores do martírio e até regozijar-se com elas. No caso dos santos, são os mártires que manifestam este factor distintivo, como se fossem imunes à dor, tal como Santo Antolim ("e el rei mandou tirar a sancto Antolim e o fez meter eu hũa tina e deitarom sobre elle chumbo derretido e pedra enxofre e esteve dous dias e duas noites que nom lhe empeceo cousa nenhũa, mas antes dizia que estava em mui doces banhos e em grande folgura" ${ }^{, 51}$ ), os mártires Crispino e Crispiniano que, sofrendo martírio, nada sentiram ("como se estevessem em deleites e quenturas de estio (...). E logo o anjo os guardou do fogo sem aleijom"52), os mártires Veríssimo, Máxima e Júlia (“despedaçavam todas as carnes e nervos atee as entredanhas (...) mas a divinal virtude sobrepojava todo tormento humano e elles com faces allegres mostravam grande prazer do espirito"53), e São Jorge ("Este espantoso genero de tormento sofreo o sancto com grandissimo animo" ${ }^{, 54}$ ).

Antecipando o martírio físico final em nome da redenção, Lancelot termina os seus dias a prestar serviço religioso numa ermida, na qual é privado da relação com o mundo exterior:

"E tanto que foi desarmado foi a ũũ altar de Santa Maria que i estava e ficou os geolhos ante el e jurou que, se Deus e Santa Maria e os santos o ajudassem, que ja mais nom se partiria do serviço de Nosso Senhor mas ficaria naquela ermida mentre vivesse." 55

\footnotetext{
${ }^{51}$ Flos Sanctorum, p. 20.

${ }^{52}$ Flos Sanctorum, p. 112.

${ }^{53}$ Flos Sanctorum, p. 156.

${ }^{54}$ LUCAS, Maria Clara de Almeida - Hagiografia Medieval Portuguesa, p. 69.

${ }^{55}$ Demanda, 702, p. 502.
} 
É aí que Lancelot se martiriza fisicamente, a fim de separar-se do mundo material e redimir-se do pecado, com vista a merecer uma vida santificada:

"IIII anos e mais foi Lançarot na ermida assi que nem ũũ homem nom poderia de afam mais e de trabalho sofrer ca el sofria em jejũar e em velar e em prezes e em orações fazer. E em estrenger sas carnes de todalas guisas que podia". 56

Lancelot, porém, não é imune à dor. Ele não é um mártir protegido pela mão divina. A dor é necessária à sua nova condição. Ele utiliza-a como prova de renúncia.

É essa postura de renúncia que os cavaleiros do Graal começam por enveredar. Boorz adopta uma conduta mendicante, procurando redimir os pecados, de forma que Meraugis, ao encontrá-lo, não o reconhece (nem aos seus companheiros):

"E quando el viu os III homens bõõs pero que os nom conoceu, houve deles gram doo porque os viu andar descalços e bem lhi semelhou que eram bõõs e honrados e de bõa vida. E ele assi estando de cavalo lhis preguntou:

- Que homens sodes?

E eles responderom:

- Nós somos homens pecadores que fazemos peendença de nossos pecados. E bem nos aveeria se per tam pouca lazeira podéssemos salvar nossas almas." 57

${ }^{56}$ Demanda, 705, p. 503.

${ }^{57}$ Demanda, 709, p. 506. 
No final do texto da Demanda, Boorz recolhe-se numa ermida, afastando-se do castelo de Lancelot, a Joiosa Guarda, e abraçando o ideal de pobreza:

\begin{abstract}
"E enviou dizer aos de Gaula e aos de Gaunes que fezessem rei quem quisessem ca ja mais el nom tornaria alá. E foi-se com o arcibispo e com Bliobleris a pee e mui pobremente quem bem catasse aa sa alteza e como era de gram guisa." 58
\end{abstract}

Na Demanda, Persival faz-se eremita perto da cidade de Sarraz, depois da morte de Galaaz:

\begin{abstract}
"Persival se meteu ermitam em ũa ermida fora de vila e pesou muito aos da vila que já haviam posto entre si que o fezessem rei. Mais el nom quis e disse que Deus nunca o fezesse rei tam longe de seus amigos e do reino de Logres. (...) Ũũ ano e dous meses viveu Persival na ermida. Entom passou deste segre e feze-o Boorz soterrar no Paaço Espirital com sa irmãã e a par de Galaaz.",59
\end{abstract}

Embora os demais encontrem refúgio espiritual na reclusão, somente Lancelot adopta comportamentos ligados à negação do corpo e à consequente purificação do pecado carnal, jejuando e oferecendo-se fisicamente ao sacrifício, flagelando o próprio corpo.

Galaaz não passa por nenhum destes processos. Ele é aquele que mais se identifica não com o modelo do santo, mas com o do redentor. Ao nível dos feitos heróicos, Galaaz realiza-os, nomeadamente na libertação das donzelas escravas do Castel Felom, presas por Arpion ${ }^{60}$, e justando com cavaleiros que o desafiam. Galaaz revela excepcionalidade

\footnotetext{
${ }^{58}$ Demanda, 708, p. 505.

${ }^{59}$ Demanda, 629, p. 457.

${ }^{60}$ Demanda, 504, p. 373.
} 
heróica. Mas age como salvador. Na cidade de Sarras, Galaaz torna-se rei e cura os doentes por milagre ("E Galaaz esto dizendo, provou o homem se se podiria erguer. E achou-se são como se nunca houvesse mal” ${ }^{\prime 61}$ ). Outro caso é o da dona sandia, que se curou com a acção de Galaaz contra o mal, por intervenção divina:

“- Ai, Galaaz! Santa cousa e bem aventurado corpo, (...) bẽẽnto seja Deus que te aqui dussi ca de ta vinda me é tam gram bem (...). Este foi o diaboo que dous anos me teve e mais há mim feito muito mal (...).

E Galaaz o gardeceu muito a Nosso Senhor e dissi aa dona:

- A mim nom no gardeçades, mas a Jesu Cristo que vos esto fez, que há doo dos pecadores quando lhe praz." 62

O herói eleito morre no momento em que o Santo Graal vai miraculosamente para o céu (Tam toste que el foi morto avẽo ũa gram maravilha que Boorz e Persival virom que ũa mão veo do céu mas nom virom o corpo cuja a mão era e filhou o Santo Vaso e levou-o contra o céu",63).

Os milagres situam-se no plano do maravilhoso. Trata-se de um "outro mundo" cristão, paralelo ao Outro Mundo feérico dos heróis. Funciona ao mesmo nível simbólico do maravilhoso, ou seja, no plano de tudo aquilo que não tem explicação lógica, tal como a cura dos doentes, a conversão automática dos infiéis (pela visão, pela palavra ou pela graça), a transformação dos lugares sagrados (ou do seu próprio corpo após a morte) em fonte de alimento, milagre ou cura (água, terra, erva), ou abstinência de comer e beber, alimentando-se somente da Graça divina, tal como descrevem as narrativas hagiográficas relativamente a Santo Antolim ("e esteve com elle o anjo sete dias e sete

\footnotetext{
${ }^{61}$ Demanda, 624, p. 455.

${ }^{62}$ Demanda, 401, p. 301.

${ }^{63}$ Demanda, 628, p. 457.
} 
noites que nom comeo nem bebeo"64) e São Victores ("quis soo no deserto morar com jejuum e oraçom continua e abstinencia do comer e do beber e servir a Deos"65).

Os três cavaleiros (Galaaz, Boorz e Persival) são eleitos para a aventura do Graal, depois de Galaaz ter curado o rei Peles ("Cavaleiros compridos de fé e de creença, escolheitos sobre todolos outros cavaleiros pecadores" ${ }^{, 66}$ ), mas apenas Galaaz recebe a comunhão com a hóstia do manjar do $\mathrm{Graal}^{67}$, revestindo-se da sua dimensão crística e de salvação. Galaaz comunga, assim, da sua parcela divina, pois agira como instrumento de Deus e mediador do bem e da cura.

Na verdade, Galaaz não chega a pertencer a dois mundos e o seu percurso mais se identifica, logo à partida, com a santidade do que com o heroísmo. Nascido da perfeição cavaleiresca do pai e da pureza da mãe, Galaaz é gerado perfeito. Não tem mácula nem passa por tentações, recebendo a luz do Graal como um sinal de eleição para transpor um mundo divino só a ele acessível.

\section{Renúncia ao mundo cavaleiresco}

O herói renuncia ao mundo, o que equivale a separar-se dele. Isso implica uma mudança de condição irreversível na sua evolução. O cavaleiro, ao entrar no caminho da edificação, torna-se um novo homem, que renasce para outro estado de maturação. Um excerto da narrativa hagiográfica de São Pero Gonçalves refere a transfiguração de um jovem cavaleiro mundano em santo:

“(...) devestio se do mundo e aquelle pee que parecia que nelle metera mui asinha o tirou, tomando a Ordem dos Preegadores. E espe//dindo de si o velho homem do mundo com todos seus actos vestio de Jhesu

\footnotetext{
${ }^{64}$ Flos Sanctorum, p. 18.

${ }^{65}$ Flos Sanctorum, p. 70.

${ }^{66}$ Demanda, 598, p. 436.

${ }^{67}$ Demanda, 599, pp. 436-437.
} 
Christo e dos costumes e virtudes de relegiom. E logo assi supitamente foi mudado em outro homem, estando em grande aproveitamento e muitos assi da Ordem como do povoo, vivo e espiritual exemplo ja posto em alto graao de virtudes (...).",68

A mudança reflecte a passagem da vida cavaleiresca à vida santa. Contrariamente ao herói medieval, que comunga da ambivalência dos mundos e a isso deve a sua índole heróica (à passagem e evolução entre reinos opostos), o santo, na altura da sua cisão relativamente ao mundo, sofre uma passagem que é definitiva, determinante de uma nova condição, não cíclica, da qual não há regresso. Lancelot, Boorz e Persival transitaram entre mundos opostos onde exerceram as suas façanhas heróicas. Circularam entre reinos distantes e criaturas feéricas. Todavia, conseguiram regressar sempre. Mas a partir do momento em que evoluem para a santidade, fecham-se nesse novo mundo do qual já não saem, perdendo, por conseguinte, aquilo que os caracteriza como heróis.

A promessa de uma eternidade recompensadora prende o herói numa dimensão unilateral, necessária à condição de santidade. Nessa dimensão não há outros elementos de composição senão a própria divindade. O herói, que tinha transitado entre mundos (Logres, a Terra Gasta, os reinos das fadas, castelos guardados por cavaleiros e criaturas mágicas, entre muitos outros) e que se tinha socorrido de elementos mediadores essenciais à sua composição (armas, escudos, cavalos, donzelas e outros cavaleiros), vêse agora, no seu destino ascético, confrontado unicamente com a divindade, sem outros elementos com os quais se confrontar e estabelecer a sua identidade, pois esta passa unicamente a reflectir-se em Deus, ficando o santo limitado a um mundo sem retorno, onde não há a presença do outro em relação ao qual o herói se define: Lancelot afasta-se de Guenièvre e dedica-se à imagem de Deus, Persival prescinde de Blanchefleur (a sua amada em Li Contes del Graal), a partir da Vulgata, momento em que se junta aos companheiros do Graal, e Boorz não volta a encontrar a donzela com quem concebeu

\footnotetext{
${ }^{68}$ Flos Sanctorum, p. 248.
} 
Alaim o Branco (Helain le Blanc na Vulgata), marca do seu único pecado carnal, ao tornar-se duplo de Galaaz na demanda do Graal.

A santidade de Galaaz assume, pois, contornos diferentes, pois ele é o cavaleiro desejado e aquele que tem a função redentora de salvar o rei do Graal. Sem pecado e sem escolha, Galaaz é o cavaleiro puro cuja missão não pode culminar senão na santidade. Afastando-se dos outros e do mundo, escolhendo mesmo o momento da sua morte, Galaaz não se relaciona afectivamente senão com Deus.

Os mediadores da relação do herói com outras personagens, designadamente com a amada, são substituídos pelos intermediários na relação com Deus, à semelhança dos santos mártires. Segundo Peter Brown, "L’homme des II et III' siècles avait un sens aigu de la multiplicité du moi et d'une chaine d'intermédiaires qui, partie du moi, parvenait, même si c'était en un point très éloigné, jusqu'à Dieu"69. De facto, os santos ligam os outros a Deus, mas eles mesmos não se ligam aos outros. Para além disso, recebem visões e ouvem vozes do mundo da divindade e deixam de efectuar o contacto com o mundo exterior.

Os santos não pertencem nem decidem pertencer a este mundo. De onde quer que parta a divisão dos mundos (da eleição ou do arrependimento), há sempre um problema de duplicação que compromete o santo. E como não pode pertencer a dois mundos, o santo muda para uma condição única.

\section{Comunhão com o intemporal}

Tanto o herói como o santo são modelos de virtude. Enquanto o caminho da santidade se caracteriza por uma mudança separadora, o percurso destes heróis sofre uma confrontação e integração a cada momento. A vida do santo obedece a um esquema simbólico que tem como base uma separação relativamente ao mundo. As narrativas hagiográficas enaltecem a vitória do bem sobre o mal, privilegiando o elogio da virtude. Em contrapartida, a cavalaria é uma itinerância necessária à composição da

\footnotetext{
${ }^{69}$ Op. Cit., p. 72.
} 
personagem, mas incompatível com a fixação que é condição para a perfeição. Essa perfeição só pode ser atingida no fim do percurso, com o elemento feminino, o "outro" por excelência no qual o herói se contempla. Mas no mundo dos santos não há "outro", não há oposto com o qual se possam relacionar, a não ser Deus. E não havendo alteridade deixa de haver evolução, estagnando o santo na eternidade intemporal.

Lancelot, Boorz e Persival fizeram a única escolha permitida a quem estivera em contacto com a aventura suprema. A hipótese da comunhão com o divino não está no Graal, mas dá-se com a renúncia ao mundo e a entrada na vida monástica. O esquema heróico, assente na composição da personagem através de elementos mediadores, dá lugar ao esquema da unilateralidade em direcção ao divino. Lancelot e Boorz, ao experimentarem uma infância feérica e estarem orientados para um percurso de cavalaria, entram na santidade pela via do monasticismo, a qual prevê a separação em relação ao mundo através do arrependimento.

Lancelot havia sido eleito como cavaleiro do Graal. Mas a eleição divina não correspondeu à sua, quando desafiou o destino que lhe estava reservado, fazendo a escolha do pecado, uma escolha própria que se sobrepôs à escolha alheia, divina.

Boorz, de certa forma, é desculpabilizado do seu pecado por ter sido induzido em erro pelo encantamento da donzela, concebendo Alaim o Branco, mas ainda assim quebrou a condição necessária à pureza absoluta o que, de algum modo, abona em favor da eleição de Galaaz, a qual, aliás, já estava predestinada, afastando a hipótese de os demais cavaleiros, ainda que com a melhor das condutas, poderem acabar a mesma aventura.

Persival fora eleito, mas a hesitação própria (que começa no texto de Chrétien de Troyes) pôs em causa a vontade divina, pelo que a vida monástica se revela o único caminho para a ascese, como que numa atitude de arrependimento tardio quanto ao desvio da sua eleição.

Galaaz apresenta-se como uma excepção em relação à atitude de mudança de conduta. Este herói não renuncia a nenhuma amada para seguir o seu destino nem se arrepende. Ele é o cavaleiro imaculado que exerce a função de salvador do reino do Graal, situando-se num plano à parte. Galaaz recupera uma velha ordem em decadência, 
redimindo o tempo e o espaço. Não renuncia ao mundo exterior, pois nunca lhe pertenceu, nem escolhe a contemplação do divino, pois ele é que fora escolhido por Deus. Para Galaaz, a perfeição não é um estado a atingir, porque ele já é perfeito. E é por isso que Galaaz, apesar de ser um modelo de cavalaria, em feitos e valores, se diferencia da condição heróica dos demais cavaleiros, cujo percurso de maturação visa aperfeiçoar as suas características.

Os heróis arturianos do Graal distinguem-se, pois, dos santos das narrativas medievais. Contudo, enveredam por um caminho semelhante a um percurso hagiográfico. Mas, apesar de evoluírem em direcção à santidade, para nela entrarem estabelecem um corte com a vida heróica. E essa transição não é reversível. Todavia, é a sua imagem heróica que continua a prevalecer.

Este estudo vem, pois, acrescentar aos heróis do Graal a imagem ascética diluída no seu heroísmo cavaleiresco, devolvendo-lhes um papel sem o qual as suas funções heróicas não são claramente compreensíveis.

Se o heroísmo prevê uma atitude distinta da santidade, o certo é que estas personagens literárias ascendem a um plano mais complexo, que contempla uma visão mais completa do cavaleiro medieval. 


\section{Bibliografia:}

\section{Fontes impressas:}

A Demanda do Santo Graal. Ed. Irene Freire Nunes. Lisboa: I.N.C.M., 1995. ISBN 97227-077-9

CHRÉTIEN de TROYES - Perceval ou Le Conte du Graal. Ed. Jean Dufournet. Paris: Flammarion, 1997. ISBN 2-08-070814-7

Ho Flos Sanctorum em Lingoagẽ: os Santos Extravagantes. Ed. Maria Clara de Almeida Lucas. Lisboa: INIC, 1988.

JACQUES de VORAGINE - La Légende Dorée. Paris: Seuil, 1998. ISBN 2-02034501-3

La Mort le Roi Artu: roman du XIIIe siècle. Ed. J. Frappier. Genève: Droz, 1964.

Lancelot: roman en prose du XIIIe siècle. Ed. Alexandre Micha. 9 vols. Genève: Droz, 1978-1983.

La Queste del Saint Graal: roman du XIIIe siècle (atr. a Gautier Map). Ed. Albert Pauphilet. Paris: Honoré Champion, 1980.

Le Didot-Perceval, according to the manuscripts of Modena and Paris. Ed. William Roach. Genève: Slatkine, 1977.

\section{Estudos:}

ALMEIDA, Ana Cristina Rui - "Um modelo de formação monástica oriental: em torno do ideal de pobreza na Escada... de Clímaco, e em S. Agostinho, S. Bento e S. Francisco". In LARANJINHA, Ana Sofia e MIRANDA, José Carlos Ribeiro (org.) Modelo: Actas do V Colóquio da Secção Portuguesa da Associação Hispânica de Literatura Medieval. Porto: Faculdade de Letras, 2005, pp. 45-55. ISBN 972-8932-05-7 BROWN, Peter - Le Culte des Saints. Paris: Cerf, 1996. ISBN 2-204-05476-3 
BUESCU, Maria Gabriela - Perceval e Galaaz, Cavaleiros do Graal. Lisboa: ICALP, 1991. ISBN 972-566-152-4

CAMPBELL, Joseph - The Hero with a Thousand Faces. New York: Princeton University Press, 1973. ISBN 0-691-01784-0

CHORA, Ana Margarida - Lancelot - do mito feérico ao herói redentor. Lisboa: Colibri, 2004. ISBN 972-772-525-2

ELIADE, Mircea - Mitos, Sonhos e Mistérios. Lisboa: Ed. 70, s.d. ISBN 972-44-0486-2

ELIADE, Mircea - Méphistophélès et l'Androgine. Paris: Gallimard, 1995. ISBN 2-07032889-9

GODINHO, Helder - "A Poesia, o Amor e a concepção do Mundo". In GODINHO, Helder (org.) - A Imagem do Mundo na Idade Média: actas do colóquio internacional. Lisboa: ICALP, 1992. pp. 35-39. ISBN 972-566-173-7

HOROWITZ, J. - "La diabolisation de la sexualité dans la littérature du Graal au XIIIe siècle: le cas de La Queste del Saint Graal”. In WOLFZETTEL, Friedrich (ed.) Arthurian Romance and Gender - selected proceedings of the XVIIth International Arthurian Congress. Amsterdam - Atlanta: Rodopi, 1995, pp. 238-250. ISBN 90-5183$635-X$

HUCHET, Jean-Charles - Essais de Clinique Littéraire du Texte Médiéval. Orléans: Paradigme, 1998. ISBN 2-13-042297-7

LASH, John - The Hero. London: Thames and Hudson, 1995. ISBN 0-500-81047-8

LOOMIS, C. Grant - King Arthur and the Saints. Speculum, VIII, 4 (Oct-1933), pp. 478-482.

LUCAS, Maria Clara de Almeida - A Literatura Visionária na Idade Média Portuguesa. Lisboa: ICALP, 1986.

LUCAS, Maria Clara de Almeida - Hagiografia Medieval Portuguesa. Lisboa: ICALP, 1984. 
MARTINS, Mário - Alegorias, Símbolos e Exemplos Morais da Literatura Medieval Portuguesa. Lisboa: Brotéria, 1980.

MARTINS, Mário - A Vida e Morte de Galaaz. Lisboa: Brotéria, 1982.

MARTINS, Mário - Estudos de Cultura Medieval. 3 vols. Lisboa: Brotéria, 1980-1983.

NEVES, Leonor Curado (coord.) et al. - Matéria de Bretanha em Portugal: actas do colóquio. Lisboa, Colibri, 2002. ISBN 972-772-331-4

PAGELS, Elaine - Os Evangelhos Gnósticos. Porto: Via Óptima, 1999. ISBN 9729360-10-3

ROBERTSON, Duncan - The Medieval Saints' Lives Spiritual Renewal and Old French Literature. Lexington: French Forum, 1995. ISBN 0-917058-90-9

SOARES, Lina - "Poder e fé no monasticismo feminino: de Macrina a Clara de Assis". In SANTA BÁRBARA, Maria Leonor et al. (org.) - Identidade e Cidadania: da Antiguidade aos nossos dias - Actas de Congresso. 2 vols., Porto: Papiro Editora, 2010, vol. I, pp. 279-287. ISBN 978-989-636-493-9

ZĂVĂLEANU, Laura Lazăr - "L'itineraire symbolique de la quête initiatique dans le monde de l'au-delà et le sens de retour'. In CARRETO, Carlos F. Clamote (coord.) Lors te metra en la voie... Mobilidade e Literatura na Idade Média - Mobilité et Littérature au Moyen Âge - Actas do Colóquio Internacional. Lisboa: Universidade Aberta, 2011, pp. 197-208. ISBN 978-972-674-703-1 


\section{COMO CITAR ESTE ARTIGO}

\section{Referência electrónica:}

CHORA, Ana Margarida - “Os cavaleiros do Graal e o anti-heroísmo hagiográfico". Medievalista [Em linha]. No12, (Julho - Dezembro 2012). [Consultado dd.mm.aaaa]. Disponível em http://www2.fcsh.unl.pt/iem/medievalista/MEDIEVALISTA12lchora1208.html.

ISSN 1646-740X.

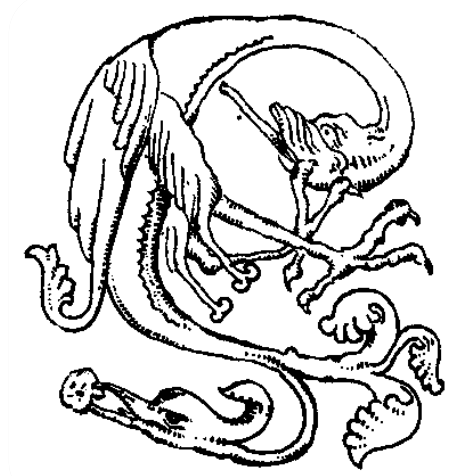

